\title{
A Prospective Study on the Application of MOOC in Teacher Professional Development in China
}

\author{
Zhaolin Ji*, Yanhua Cao \\ College of Education Science, Nantong University, China
}

Copyright $(\mathrm{C} 2016$ by authors, all rights reserved. Authors agree that this article remains permanently open access under the terms of the Creative Commons Attribution License 4.0 International License.

\begin{abstract}
Teacher professional development is the process of constantly strengthening professional attainment, broadening academic knowledge, enhancing the professional skills, and improving teaching ability. With the reform of learning science and the development of Information and Communication Technology (ICT), the traditional mode of teacher professional development is confronted with challenge, and the new emerging MOOC system provides a new path for teacher professional development. The MOOC system is an important tool for teacher professional development because of teacher's professional characteristics, teacher's needs, and the cost of promotion. The application of MOOC system to teacher professional development, however, is still in the trial stage, and we need to carry on emphatically analysis on the policy, quality and value of the application of MOOC to teacher professional development. Coursera carried out projects of teacher professional development actively, and developed a series of teacher education curricula in cooperation with institutions of higher education and social culture institutions, which can be regarded as the pioneer and model in the field. At present, the application of MOOC system to teacher professional development is still in the stage of empiricism studies, and data-driven research in this field is needed, so as to deal with various potential obstacles, overcome different difficulties and solve possible problems.
\end{abstract}

Keywords MOOC, Teacher Professional Development in China, Prospective Study

\section{Introduction}

The development of learning science and the evolution of information and communication technology provides multiple methods for teacher professional development. The application of remote educational system in teacher professional development is one of the most important methods, which is still in the process of evolving. A lot of factors contribute to the process, including the emphasis on professional teaching behavior, the need on the standard teaching ability, the increased amount of students, the diversified need of students, and the changing teaching technology. The changing teaching technology enhanced remote educational system through utilization of multimedia, cooperative teaching and learning design, individualized teaching and learning procedure. The application of teaching technology fostered the effect and attractiveness of remote educational system, which also oriented the rebuilding, redesigning, and redeveloping the educational system. This becomes one of the important components of educational system reform.

MOOC is the latest remote educational system, which exerts profound impact on traditional teaching mode, leads a new trend in education, and also provides a new method for teacher professional development. MOOC is a hot topic in recent educational research. Lots of researchers investigated MOOC learners' participation and the effectiveness of MOOC, and educational institutions also sensed the enormous impact of MOOC on educational reform. According to Clay Shirky [1], the extensive application of MOOC will surely overwhelm traditional education, just like what MP3 brought to the music industry. MOOC starts to step into teacher professional development. Previous research indicated that, in teacher professional development, MOOC enjoys advantages in cost and educational results [2]. However, there are still risks, which might compromise the application of MOOC in teacher professional development. Teachers are still reluctant in utilizing MOOC as a new teaching method, and MOOC is also facing a lack of resources on teacher professional development. The majority previous research on MOOC concentrated on higher education and life-time education, but few touched its application on teacher professional development. Therefore, there is a need to conduct experiments to explore the application of MOOC in teacher professional development. 


\section{On the Necessity of Applying MOOC to Teacher Professional Development}

Teacher professional development is a growing research area. Linda [3] claimed that teacher professional development had not reached a clear and precise definition in a narrow sense, and that it could be considered as a process in a broader sense, through which teacher can achieve their emotional and professional development with a series activities. In another word, teachers participate in various learning activities to practice their professional knowledge and skill. Although teachers are willing to take those learning activities, they are facing lots of difficulties such as time conflict, resource shortage, and bad organization. In China, the amount of teacher has reached 12 million, and all of them have to take professional development through degree programs or non-degree programs. Chinese government requires their teachers to take more than 240 hours professional learning every 5 years. This includes novice teacher training, veteran teacher development, and prominent teacher enhancement. Chinese government, from county to country, is responsible for the fund and organization of the teacher professional development. In the period between 2010 and 2015, the China Central Government granted 0.55 billion in training more than 7 million teachers through face-to-face training and various kinds of remote teaching. However, the required online learning and evaluation were far from satisfaction. The lack of high-quality resources, effective monitor and evaluation methods, efficient communication strategy, and sound management compromised teachers' learning passion and training outcome [4, 5]. Now China educational department have noticed the great influence of MOOC, and start to employ it in teacher professional development.

First, massive open online courses can meet the need of teacher professional development at large. MOOC connects thousands of learners and educators throughout the world by the application of online open courses [6]. Through MOOC, teachers can get access to regular educational courses with little barriers. Literally, anyone can reach any courses anywhere at any time. In addition to some traditional education training courses, a series of courses on life-lone learning and hybrid learning are emerging. MOOC has become an important tool for some teachers to gain professional development after getting their degrees. MOOC has become an effective solution to provide high quality teacher professional development at a low cost.

Second, MOOC enables teachers to learn according to their individual needs. MOOC brings together excellent educators, technicians, and professional courses in almost all the areas. The subcategories of MOOC, such as XMOOC and cMOOC, provide online courses with different teaching and learning philosophy, which could satisfy the need of different learners [7]. MOOC could also be utilized with Wiki, blog and other message apps, which could help them take notes, write down their reflection, have discussion, and establish learning community, so as to achieve satisfactory learning results.

Third, MOOC also provides powerful support to teachers' daily work in addition to its effect on fostering teachers' professional development. MOOC promoted the development of hybrid learning and Flip classroom teaching, which bring drive to the educational reform. Teachers can gain all kinds of knowledge from MOOC, and bring it to their classroom teaching, which will make student's classroom learning more efficient. When learning through MOOC, teachers can establish learning community on the base of similar interest or career to promote communication and interchange. This will in turn be helpful to construct a net of professional development with participants from the whole world through MOOC. MOOC also provides an effective way for teacher professional development at a relative low cost. The hybrid of MOOC and traditional classroom teaching might give a good method for teacher professional development. The hybrid program can cut down cost by the application of MOOC and gain profit through license fee and accreditation fee.

\section{The Application Feasibility of MOOC in Teacher Professional Development}

MOOC is a hot topic in education area, but it is still a newcomer in teacher professional development. The feasibility of its application in teacher professional development still needs to be evaluated. This section will deal with such a question from three most influential perspectives, including MOOC-related policy, quality, and value.

\subsection{Policy}

MOOC can enhance teachers' learning experience and meet their various needs, so MOOC has a promising future in its application to teacher professional development, and it will promote the reform on teacher education to some extent. Teacher professional development is always guided by national policies. Therefore, supportive policies are the base and presupposition for the application of MOOC to teacher professional development. Teachers' social status is rising recently, and educational degrees are becoming more and more attractive. This trend reflected the recognition of teacher's job from the society, and it also carries people's higher expectation and demands towards teachers. This calls for teacher professional development throughout the whole career period. Therefore, various policies were issued to promote teacher professional development, and lots of digital education resources were developed to serve the teachers. In China, for example, the National Education Department [8] launched National Elite Teacher Education Course Pool Program in November 2012, and announced first 200 granted course in April 2013. This is China's response to the education reform in the digital era, which demonstrates China's emphasis on teacher education. The 
Teacher Bureau of National Education Department [9] claimed its schedule on promoting teacher administration and digitalized teacher education, continuing National Elite Teacher Education Course Pool Program, and designing and popularizing excellent MOOC courses on teacher education. The government has recognized the importance of teacher education reform with digitalization, encourages and facilitates the development of MOOC courses on teacher education, and provided supportive policies for the application of MOOC in teacher professional development. The supportive policies, of course, also face many challenges, and the biggest problem is lack of fund. The government is the administrator who runs the education system, and they also grant the educational institutions through national budget. In China, government guides educational legislation, sets national education aims, and directs its education department to develop proper policies to realize the schedule. The policies that guide the application of MOOC in teacher professional development define the fund allocation. In such administration frame, fund and quality are always related to effectiveness and efficiency. Although the government designed some policies and granted certain amount funds, the great amount of educational institutions competed fiercely for the limited amount of grants. The competition for the economic benefits will surely have bad impact on the quality of MOOC projects.

\subsection{Quality}

The education effectiveness of MOOC system in teacher professional development is affected by both fund and its characteristics. MOOC makes it possible for teachers to have classes at any time at any place, which breaks the limitation of synchronic education. The openness and flexibility of MOOC has changed the traditional understanding of classroom teaching. With MOOC, every education-related party can contribute to its quality improvement. The supportive policies from the government provides necessary grants, and the contributions from the MOOC consumers, especially teachers, will guarantee the quality of MOOC in this area.

Generally, the application practice of MOOC in teacher professional development is far from enough, and the traditional teacher professional development just uses workshop to develop teachers' skills in certain areas. The traditionally granted credits are no longer the only way to prove teachers' ability, and online learning is gaining popularity among teachers in their professional development. The online learning manage system, together with electronic evaluation folder, has won over lots of teachers. MOOC provides a new plat form for teachers to demonstrate, maintain, and evaluate their career proficiency[10]. However, MOOC should evolve from its extensive development mood, develop application standards for teacher professional development, and establish scientific and humane operational mechanism.
First, scientific and normative standards are the keys. Establishing standards is a more and more popular practice in teacher education reform, which is also a sign of professionalization of teacher education. Normative standards are the products of the quality assessment in certain fields, which also reflect the needs of government. Therefore, professional association and education department of the government cooperate frequently to set up standards. Through such a process, teachers' professional needs and social requirements are all considered in issuing standards in the form of policies or reports. Those standards will be both professional the authoritative. The application of MOOC in teacher professional development also needs such standards. The accreditation with certain training activities will secure the relation between education technology and education quality. Of course, the standards also need some formal recognition, including institutional recognition (from educational institution or professional association) and program recognition (from some professional training programs or continuous education programs).

Second, the effectiveness of MOOC in teacher education development is the core concern. Many traditional teacher education providers and teachers still doubt that remote education could ensure the quality of teacher education as what the traditional school education could do. Obviously, the delivery method is not the key to the function. Garrison [11] evaluated and analyzed many remote teacher education, and claimed that the remote programs could achieve the same quality as those face-to-face programs. However, his research did not involve any network or information technology. Simpson [12] proved with experiments that there was no significant difference between the teaching effect of remote and face-to-face teacher education programs. However, remote programs enjoyed advantage in time arrangement and fund cost. Simpson also found that network and information technology have positive influence on remote teacher education programs, which sometimes could be determinative. MOOC, as an upgraded online learning system, performs much better in objective setting, content normalizing, methodology designing, and program evaluating. Therefore, it can provide a good service for teacher professional development.

\subsection{Value}

All the teacher professional development programs have their consistent, continuous, and interrelated core value, which aims to secure teaching quality by developing teachers' knowledge and skills on curricula setting, teaching methods and social environment. Theoretically, these intricate knowledge and skills can be achieved through a series of progressive teacher professional development programs. In the programs, teachers can exchange and cooperate with other teachers, scholars and experts in education, and they can also achieve more thorough communication with students to gain valuable feedback. 
Besides the necessary knowledge, skills and strategies, teachers need to reflect on their own education practices, which is essential for their life-long learning and commission to teaching course [13]. The core values of on-campus teacher professional development programs are in accordance with the life values and career philosophy that college students are pursuing [14]. However, when the teacher professional development programs are put in a virtual environment, the impact of MOOC system on the programs still remains unknown.

In order to meet the needs of online teacher professional development, all the online education resources need to be adjusted, including online education facilities, technology development, and assessment system. This also needs the guide of online learning philosophy and support from online learning experience. For example, reliable online learning infrastructure and advanced technology should support teachers' online learning and promote teachers' communication and cooperation in the programs. The application of MOOC to teacher professional development is a social-driven potential, the realization of which needs the support from online learning technology and facilities. There are great differences between the virtual online space in MOOC and the face-to-face classroom environment. How to make use of the differences and adjust to online learning environment requires not only theoretical guide and program design, but also practical experience and effective assessment. Moreover, the new relationship created in such virtual environment may also go beyond people's expectation. According to Anderson and Simpson [15], teachers in a professional development have established a rational society among the participants in their online discussion group. They found that those teachers in online programs could make the same achievement as those in traditional classroom programs, and claimed that the virtual learning society could help teachers reflect on their professional development, which also could reflect the change of the society and the reform of the education.

\section{Coursera's MOOC on Teacher Professional Development:}

\subsection{What is Coursera?}

MOOC has forced universities to reassess its value in the campaign of online education. Coursera, as one of the three major MOOC providers, leads the trend, helping higher education institutions to participate in the movement, and accreditating the online learning credit hours. Now, Coursera expands its courses to include teacher professional development programs by adding teacher professional development courses and creating school of education column in its curricula. Coursera has launched first 42 courses to support elementary and middle school teachers' professional development.
MOOC has evolved into three major forms: xMOOC, cMOOC and quasi-MOOC. XMOOC is mostly employed by traditional educational institutions, in which teachers are experts while learners are consumers. cMOOC is an open decentralizing discrete course management system, which is based on connectivism. Quasi-MOOC is a relative simple resource management system, which provides web-based open education resources [16]. Coursera is based on cMOOC framework, provides massive course resource center for students to read, and establishes online course platform for their autonomic learning. In this process, blogs, forum, and instant message applications are used for communication, distribution and collaboration. In teacher development program, Coursera provide teachers all the online courses for free, and will issue a certificate, with only 50 dollars fee, to verify his/her learning after he/she complete all the courses [17]. Andrew, one of the cofounder of Coursera, claimed that online teacher professional programs can create more opportunities for teachers to participate and help educational institutions to save fund, because lots of middle schools and elementary schools lack of resources for effective teacher professional development [18]. Professor Koller, from Stanford University, another cofounder of Coursera, expected to support millions of teachers from all over the world to develop their knowledge, skills and social network with massive free educational resources of quality on Courera [19].

\subsection{Coursera's courses for teacher professional development}

Coursera has cooperation with schools of education from University of Washington, University of Virginia, Johns Hopkins University and Vanderbilt University to develop high-quality teacher professional development courses, like "Effective Classroom Interactions" from "University of Virginia and "Engaging Students through Cooperative Learning" from Johns Hopkins University. "Effective Classroom Interactions", an iconic course of Curry School of Education in University of Virginia, aims to improve the teacher-kid communication quality. The course is famous and influential for the long-term tracing study [20]. In order to help more yearly childhood teachers to foster children's social cognitive, emotional, self-discipline, and literacy development with appropriate teacher-kid interaction skills, Coursera collaborated with University of Virginia to adapt the course into a MOOC course. Bridget Hamre looks at MOOC as a great opportunity, which enables them to deliver the course to, have test with, and create learning community among early childhood teachers all over the world [21]. " Engaging Students through Cooperative Learning" is also a classic course with 25 years history at Johns Hopkins University. Professor Paul D. Miller gives 3-5 hours lecture every week for this course. The objectives of this course are to define the cooperative learning and its relation with learners, to describe how to make use of cooperation on the base of individual responsibility and equality in group work, 
to investigate the four fundamental theories, and to tackle the influence of cooperative learning on the development of skill and cognition in 21 century [22]. Johns Hopkins University is the leader in the research on the philosophy, pattern and mechanism of cooperative learning, as well as its effectiveness on the fundamental courses. MOOC, undoubtedly, provided a much broader platform for teacher professional development.

Of course, Coursera also extends its teacher professional development programs into some liberal arts institutions, such as Museum of Modern Art in New York and Exploratorium in San Francisco. Museum of Modern Art, based on Coursera's MOOC platform, started a four-week course, titled Art of Inquiry, for professional development of elementary and middle school teachers. The course helps teachers to induce their students to describe the world, reach conclusions from first-hand data, and exchange with inquiry [23]. Deb Howes, the director of the digital learning center in Museum of Modern Art, said," It is natural that not all teacher know the knowledge at the museum, and that we love to cooperate with Coursera to share with teachers what we have"[24]. For years, the museum maintained teacher professional development programs in a limited scale. The collaboration with Coursera enables the programs to reach more teachers with their superb learning and sharing platform. Exploratorium is another prominent institution for teacher professional development. Exploratorium enjoys a long history in training teacher in practical learning. The cooperation with MOOC brings teachers a marvelous learning experience, which helps to integrate engineering skills and other course knowledge into elementary and middle school teaching. Now Exploratorium trains more than 500 teachers every year in their professional development course. The museum is excited about the new way of teacher professional development, which is based on virtual network[25].

\subsection{The Challenges}

In order to design excellent professional development courses for thousands of teachers, Coursera provides lots of constructive suggestions for its partners. However, there are still many questions need to be answered. First, is it feasible to apply MOOC in teacher professional development? Barnett Berry, the director of one non-profit center for teaching quality, claimed that internet and well-developed learning community break the communication barrier among teachers and make it possible to deliver various professional knowledge freely. Berry is an expert with years of experience in online education research and practice, and has knowledge of Coursera's features and model. He also point out that competent virtual mentor is the key to success. Such mentors should have professional knowledge in all disciplines and can guide high-quality online discussion and communication. Second, how to attract teachers in the whole MOOC learning process? Compared with regular courses, MOOC have more organized components, but cannot provide synchronic direct communication among teacher and students. In order to improve learners' learning experience, short dynamic video clips and online tests are frequently employed to maintain learners' interest and participation. Third, can MOOC reach the same effect as regular in-person training in teacher professional development? In USA, most districts trained their teachers regularly with lectures of specific topic, which were produced by outside consulting institutes. Teachers had no voice on the course topic, content or delivery methods. However, Schwartz insists communication, as an essential part of teaching, could hardly be realized in MOOC or other online courses [26]. The problems that teachers encountered are practical ones, which need time and cooperation to solve. The training on the MOOC platform cannot prove its advantage in this aspect. However, some teachers claimed that they learned a lot from their peers via Coursera's online learning and communication system. Those teachers established their own learning community to enhance their communication, and they also extended the learning community to strengthen their relationship. The last question is whether the Coursera courses are recognized by authorities in certain districts. This determines that whether teachers are willing to spend time and energy to work for Coursera's certifications.

\section{The Application of MOOC in teacher professional development}

MOOC has demonstrated its potential in teacher professional development. MOOC is promising for its cMOOC framework, connectivism base and scientific evaluation and certifications. However, the quality and variety of course resources still cannot meet the demand of teacher professional development. The lack of fund affected the quality and quantity of MOOC course resources, which could hardly meet the needs of teacher professional development. Till 2014, there are 58 courses related to teacher professional development, among which only one course is in Chinese. The language barrier affects the learning results and teachers learning interest [27]. Although some specialists are designing and developing MOOC courses for teacher professional development, there are still a lot to do for the preparation of professional, practical and handy teacher education courses. The present online teacher education courses are too general, and cannot meet the needs of teachers with different characteristics, different disciplines, or different districts, which compromises their educational efficiency and influence.

The long-term effectiveness and sustainability of MOOC are still debatable, but, as most researchers consent, MOOC do have long-term influence on the teacher professional development education. China government requires, in its 2015-2020 country teacher training program, to accumulate and utilize high-quality professional development resources to meet the needs of country teacher training through 
purchasing and developing online curricula and generative training curricula with grants from the government [28]. The success of MOOC depends on the primary education institutions' acceptance and its effectiveness in teacher professional development. Should the course accreditation and credit recognition problem solved, MOOC have significant advantage over traditional classes. The success of MOOC is expectable. The application of MOOC in teacher professional development will surely bring mutual benefit to both teachers and MOOC. Teachers can get high-quality teacher professional development for free, and MOOC can expand its users through the help of teachers. However, we still need time to see whether both teachers and commercial institutions can find mutual benefit. The application of MOOC in teacher professional development is still in the empirical stage, and experimental data analysis is needed for further research. Moreover, cMOOC framework and standardized learning accreditation did not bring ideal results, which still needs further investigation.

\section{Acknowledgements}

We are very grateful to the grant support from Educational Department of China on the project "Suburban Early-Childhood Teacher Professional Development, from the Perspective of Balanced Educational Development Policy".

\section{REFERENCES}

[1] Clay S. (2012). Napster, Udacity and the Academy [Internet]. [Place unknown]: [Publisher unknown]; 2012 [cited 2016]. Available from http://www.shirky.com/weblog/2012/11/nap ster-udacity-and-the-academy.

[2] Glenn MK, Mary AW, David F. Educating educators, Designing MOOCs for professional learning [Internet]. Raleigh: NC State college of education; 2014[cited 2016]. Available

fromhttp://www.mooc-ed.org/wp-content/uploads/2014/09/ MOOCsforEducatorsChapter-051614-1.pdf.

[3] Linda E. What is teacher development?. Oxford Review of Education. 2002; ( 1):123-137.

[4] Hongbo L. On the professional development of county ECE teacher. Continuing Education Research. 2012; (6): 11-12.

[5] Weiguo W. The effect of distance learning in National Teacher Professional Development Program. Continuing Education Research. 2013; (2): 51-53.

[6] Larry J. et al. NMC horizon report (2013 higher education edition). Austin: The New Media Consortium. 2013; 11-14.

[7] Yonggu W. Qing Z. MOOC: Feature and learning system. Education Research. 2014; (9): 112-120.

[8] National Education Department. Notice for National Elite Teacher Education Course Pool Program [Internet]. 2015[cited 2016]. Available from http://www.moe.gov.cn/p ublicfiles/business/htmlfiles/moe/s7011/201211/xxgk_1449 93.html.

[9] The Teacher Bureau of National Education Department. Notice to deliver the list of major tasks in 2014[Internet]. 2014[cited 2016]. Available from http://www.moe.gov.cn/p ublicfiles/business/htmlfiles/moe/s3735/201402/164775.htm 1.

[10] Mary T., Steve G. Interaction and e-learning, The student experience. Studies in Continuing Education. 2006; $3: 203-221$.

[11] Donn R. G. Blended learning: Uncovering its transformative potential in higher education. The Internet and Higher Education. 2004; 2:95-105.

[12] Mary G. S. Distance delivery of pre-service teacher education: Lessons for good practice from 2 wenty-1ne international programs. Pennsylvania State University, 2003:210-213.

[13] Ken Z. The new scholarship in teacher education. Educational Researcher. 1999; 9:4-15.

[14] Hilary P. Teacher education: the role of open and distance learning[Internet]. 2010 [cited 2016]. Available fromhttp://www.col.org/PublicationDocuments/pub_Teache rEd_Role_ODL.pdf.

[15] Bill A, Mary S. Group and class contexts for learning and support online: Learning and affective support online in small group and class contexts. International Review of Research in Open \& Distance Learning. 2004;3:1-10.

[16] Ian M. An exploratory analysis of motivation and engagement in massive online open courses. University of California Riverside. 2014; 60-65.

[17] Michael A. C. Technology strategy and management: Are the costs of "free" too high in online learning. Communications of the ACM. 2013;(4):26-28.

[18] Ellis B. Coursera online hub offers teachers development [Internet]. 2014 [cited 2016]. Available from http://www.inf ormationweek.com/software/coursera-online-hub-offers-teac hers-development/d/d-id/1109768?.

[19] Coursera. Coursera announces professional development courses to facilitate lifelong learning for teachers [Internet]. 2014 [cited 2016]. Available from http://www.marketwired. $\mathrm{com} /$ press-release/coursera-announces-professional-develop ment-courses-facilitate-lifelong-learning-teachers-1784940.h tm, 2014-02-25.

[20] CASTL. Effective classroom interactions - Development of online coursework [Internet]. 2014[cited 2016]. Available fromhttp://curry.virginia.edu/research/centers/castl/project/e ffective-classroom-interactions.

[21] Curry School of Education. Curry partners with Coursera on early childhood Education Course[Internet]. 2013[cited 2016]. Available from http://curry.virginia.edu/press-release s/curry-partners-with-coursera-on-early-childhood-education -course.

[22] Coursera. Engaging students through cooperative learning [Internet]. 2014[cited 2015]. Available from https://www.coursera.org/course/cooperativelearning.

[23] Coursera. About museum of modern art [Internet]. 2015[cited 2016]. Available from http://www.coursera.org/moma . 
[24] Ashton C. MoMA gets in on the MOOC craze, Teaming with virtual Ed giant Coursera [Internet]. 2013[cited 2016]. Availablefromhttp://www.blouinartinfo.com/news/story/928 436/moma-gets-in-on-the-mooc-craze-teaming-with-virtualed-giant.

[25] Exploratorium. Exploratorium to offer teacher professional development courses online via Coursera [Internet]. 2013 [cited 2016]. Available from http://www.exploratorium.edu/ press-office/press-releases/exploratorium-offer-teacher-prof essional-development-courses-online.

[26] Katrina S. MOOCs for teachers: Coursera offers online teacher training program [Internet]. 2015[cited 2016]. Available from

http://blogs.kqed.org/mindshift/2013/04/new-online-teachertraining-program-joins-mooc-madness/.

[27] Haishun W. Yu F. The application of MOOC in distance teacher education. Contemporary Teacher Education. 2015; (6).

[28] General Office of the State Council of PRC. Country teacher training program 2015-2020. 2015 [cited 2016]. Available from

http://www.gov.cn/zhengce/content/2015-06/08/content 983 3.htm. 